\section{A LIBERDADE E A IGUALDADE NA TEORIA DEMOCRÁTICA DE HANS KELSEN}

\author{
Ricardo Moreira Lacerda \\ Graduado em Ciências Políticas \\ Universidade de Brasília
}

\section{RESUMO}

O presente ensaio possui como objetivo analisar a relação entre os princípios filosóficos da liberdade e da igualdade na perspectiva da construção da teoria democrática de Hans Kelsen, tendo como referência básica o seu ensaio Essência $e$ Valor da Democracia (em alemão Von Wesen und Wert der Demokratie), publicado em 1929 na revista italiana Nuovi studi di diritto, economia e politica. Em um primeiro momento, pretende-se definir os conceitos de liberdade e igualdade presentes nesta obra de Hans Kelsen. Na segunda parte, será apresentada como esses dois conceitos são justificados como fundamentos da democracia e como eles são relacionados conjuntamente da doutrina do autor. Na última seção deste trabalho, será abordado o problema de como esses princípios esclarecem a concepção do Wesen (essência) e do Wert (valor) na teoria democrática de Hans Kelsen.

Palavras-Chave: Democracia; Liberdade; Igualdade.

\section{ABSTRACT}

The present essay aims to analyze the relationship between the philosophical principles of freedom and equality in the perspective of the construction of Hans Kelsen's democratic theory, having as its basic reference his essay Essence and Value of Democracy (in German Von Wesen und Wert der Demokratie), published in 1929 in the Italian magazine Nuovi studi di diritto, economia e politica. At first, it is intended to define the concepts of freedom and equality present in this work of Hans Kelsen. In the second part, it will be presented how these two concepts are justified as foundations of democracy and how they are jointly related to the doctrine of the author. In the last section of this paper, the problem of how these principles clarify the conception of Wesen and Wert in Hans Kelsen's democratic theory will be addressed.

Keywords: $\quad$ Democracy; $\quad$ Freedom; Equality.

Introdução

Além de ser amplamente reconhecido como um dos maiores juristas do século passado e sua obra ter influenciado fortemente o pensamento jurídico positivista daquele século, Hans Kelsen também foi um filósofo da política e contribuiu efetivamente com seu pensamento para elaboração de uma teoria da democracia. Durante a década de 1920 o pensamento do jurista austríaco é marcado pela profunda preocupação com a defesa das liberdades do regime democrático, neste contexto identificam-se diversas publicações do autor de cunho 
filosófico cujo objetivo era o desenvolvimento dos conceitos centrais e análise dos problemas enfrentados pelas democracias parlamentares europeias.

O jurista austríaco teve uma vida longeva, falecendo aos 92 anos nos Estados Unidos e, portanto, vivenciou atmosferas políticas e culturais distintas ao longo do turbulento século XX. Foi perseguido pelo regime nazista, observou a queda de democracias parlamentares e a ascensão de regimes totalitários na Europa e, por fim, buscou refúgio na América onde pudesse expressar livremente o desenvolvimento de suas ideias e de sua defesa da democracia. Tendo em vista este contexto, é preciso ressaltar que ao longo do período em que desenvolveu suas obras mais importantes identifica-se uma distinção entre um enfoque mais filosófico característico da década de 1920, e o enfoque mais estrito do positivismo jurídico caracterizado pela excessiva normatização do Estado. Geralmente ao se estudar o pensamento de Hans Kelsen, ignora-se o fato de que sua teoria jurídica encontra forte eco em sua filosofia política. Tal perspectiva pode ter como justificativa a estrita identificação da doutrina Kelseniana com os pressupostos epistemológicos do positivismo jurídico, sobretudo após a publicação da importante obra Teoria Pura do Direito (1934), que identifica o Estado e o Direito como duas realidades indistinguíveis e a busca incessante pela elaboração de uma teoria científica do Direito caracteriza pela ausência de juízos de valor, sobretudo em relação à justificação racional do regime democrático, e também pela forte normatização do Estado.

Desta forma destaca-se inclusive que Hans Kelsen foi um profundo defensor das liberdades democráticas, expressas, sobretudo pela salvaguarda dos direitos das minorias, em favor do regime parlamentar e, principalmente, na sua interpretação de que apenas o relativismo filosófico, entendido tanto como pressuposto epistemológico, quanto atitude em relação à realidade, como condição racional para a manutenção do regime democrático.

Após as revoluções burguesas ocorridas nos séculos XVIII na Europa Ocidental e nos Estados Unidos, e a experiência das lutas operárias do século XIX, a democracia tornou-se um lugar comum no pensamento político e nas discussões cotidianas no mundo contemporâneo. Seus pressupostos e fundamentos tornaram-se elementares para a compreensão das formas de governo existentes no mundo moderno e, uma teoria política que se dedique a analisar a questão dos fundamentos desse regime político, sempre aborda a questão dos 
valores da liberdade e igualdade, que compõem o cerne de um sistema democrático. Não obstante ao horizonte de grandes avanços no processo de racionalização e justificação do poder político, percebe-se atualmente que os valores políticos e filosóficos encontram na epistemologia e na teoria política uma série de ambiguidades e divergências quanto a seus significados e princípios elementares. Neste sentido, os ensaios elaborados durante um período de agitação na Europa, e, consequentemente, a teoria democrática de Hans Kelsen, surge como significativos exemplos de como um autor contemporâneo ainda pode abordar a questão da relação entre liberdade e igualdade de maneira original.

A preocupação de Hans Kelsen com a construção de sistemas políticos que sejam mais justos, igualitários e que, sobretudo, proporcionem maior liberdade aos indivíduos, podem ser observados ao longo de suas obras de cunho mais filosóficos, como O que é Justiça (1957) e Teoria Geral das Normas (1960). Contudo, foi em seus ensaios publicados entre 1929 e 1930 na Itália, na revista Nuovi studi di diritto, economia e politica, que a sua preocupação com a questão da democracia e dos valores que compunham sua essência, se sobressaiu de forma mais clara. Entre os ensaios publicados, destaca- se o Essência e Valor da Democracia (em alemão Von Wesen und Wert der Demokratie), publicado em sua segunda edição na mesma revista. Contudo, ressalta-se que o trabalho já havia sido publicado anteriormente em 1920 em Tübingen.

É consenso que a liberdade e a igualdade constituem-se os principais elementos que justificam o sistema democrático. Na obra de Hans Kelsen, esses dois princípios possuem papel fundamental para compreensão do sistema democrático moderno.

De um ponto de vista psicológico, a síntese de liberdade e igualdade, característica essencial da democracia, significa que o indivíduo, o ego, deseja liberdade não apenas para si mesmo, mas também para os outros, para o tu. $\mathrm{E}$ isso, somente é possível se o ego deixa de se perceber como algo único, incomparável e irreprodutível, mas, ao menos em princípio, como igual ao tu. O ego só poderá honrar a pretensão do tu a ser também um ego se o indivíduo, não considerar como essenciais as inegáveis diferenças existentes entre ele e os outros e se o ego, ou autoconsciência, sofrer uma redução parcial pelo sentimento de igualdade com os outros. É essa, exatamente, a situação intelectual de uma filosofia relativista. A personalidade cujo desejo de liberdade é modificado por seu sentimento de igualdade reconhece a si mesma no outro. (KELSEN, 2000, p. 180) 
A partir dessa afirmação, pode-se identificar claramente na vertente filosófica de Kelsen, como os princípios da liberdade e da igualdade são fundamentais para a construção da teoria democrática. É recorrente na obra do autor que as relações entre o indivíduo e a sociedade, entre a liberdade e a autoridade, entre liberdade e igualdade, são relações que constituem o núcleo do pensamento do autor.

Veremos ao decorrer deste trabalho, como Kelsen fundamenta sua teoria da democracia, no sentido de buscar uma caracterização racional-científica desta forma de governo. Será abordado, sobretudo, a questão dos princípios da liberdade e da igualdade, como eles são definidos e como se inter-relacionam no regime democrático. Cabe destacar, que Kelsen sempre buscou uma objetividade nas abordagens jurídicas e filosóficas. Para isso, o autor pretende analisar esses fundamentos, afastando-se de concepções morais, metafísicas e sociológicas que podem afetar sua caracterização.

Os Conceitos de Liberdade e Igualdade em Kelsen

Ao analisar o pensamento de Kelsen é preciso distinguir quando ele se refere à ideia e quando ele se refere à realidade. Para o autor, essa distinção é necessária, pois tanto a ideologia quanto a realidade só podem ser compreendidos na medida em que são justapostos e comparados em sua análise. A essência da democracia, segundo ele, só pode ser compreendida levando em consideração a antítese entre ideologia e a realidade. (ibid. p. 34). Nota-se que a fonte recorrente das discordâncias e interpretações distorcidas ocorre, sobretudo a partir da confusão estabelecida entre aquilo que é ideologia e aquilo do que é realidade empírica, ou seja, o que ocorre de fato na experiência dos povos.

$\mathrm{Na}$ concepção da ideologia democrática kelseniana, a relação entre indivíduo e a ordem social ocorre por meio de um problema básico: o fato de que qualquer vínculo social torna o indivíduo menos livre ou subordinado. Por outro lado, em sua essência humana, o homem sempre apresenta um impulso natural para liberdade. Esse conflito que Kelsen apresenta, é essencial para compreender como a liberdade individual é entendida em um sistema político. O problema elementar apresentado por ele sugere a impossibilidade do ser humano ser totalmente livre em um estado social. A liberdade em seu sentido essencial é uma abstração, uma vontade irrealizável no 
plano empírico. Hans Kelsen pressupõe uma visão de homem que possui um sentimento primitivo antissocial, que é capaz de encontrar sua plena liberdade apenas em um estado natural anterior a sociedade, visto que o estado de sociedade conduz necessariamente a um poder coercitivo que limita a liberdade do indivíduo. "É a própria natureza que, exigindo liberdade, se rebela contra a sociedade" (KELSEN, 2000, p. 27).

A liberdade é o princípio fundamental da ideologia do sistema democrático. Todo problema político de alguma forma está relacionado à questão da liberdade, como a liberdade política deve ser construída por meio das instituições sociais. $\mathrm{O}$ primeiro problema a ser compreendido é como o indivíduo pode ser livre em uma sociedade, se é inevitável que na própria ordem social haja sempre o peso do poder político a ser exercido sobre os homens? Para resolver este problema, Hans Kelsen retorna aos clássicos dos autores contratualistas, citando diretamente Jean-Jacques Rousseau, e destaca que para que a liberdade seja compreendida como elemento da vida social, é imprescindível que haja uma mudança de significado nas concepções de "liberdade natural" e a "liberdade política". Há um resgate nesse ponto do pensamento kelseniano das teorias do contrato social e de certa forma do estado de natureza. Para compreender como Kelsen define a liberdade nos sistemas democráticos é necessário primeiramente entender como o autor define esses dois conceitos. A liberdade natural, neste ponto Kelsen segue a linha de raciocínio dos autores contratualistas, seria a condição do homem que está fora de qualquer vínculo social, onde haveria um espaço para uma liberdade individual absoluta. Esse estado de liberdade plena seria a realização da essência humana no pensamento de Kelsen. Mas, se por sua própria natureza o homem possui necessidade de conviver coletivamente por ser um zoon politikon, como já afirmava Aristóteles em IV a.C, e, portanto, se deve haver uma sociedade, é preciso que haja normas. Se houver normas, deve haver um poder que seja capaz de editá-las. Neste ponto, Kelsen põe em relevo que qualquer relação de poder é uma relação que consequentemente tende a diminuir a liberdade do indivíduo. Desta forma, o conceito de liberdade natural não pode mais se sustentar em uma ordem social, visto que essa ordem necessariamente pressupõe vínculos sociais de dominação e que deve valer objetivamente, ou seja, deve independer da vontade daqueles que lhe estão submetidos. Bobbio (1988) confirma essa tese ao afirmar que liberdade e autoridade são dois termos antitéticos, 
onde um aumenta e o outro necessariamente diminui. Assim, a liberdade que antes era natural e absoluta, transforma-se em liberdade política.

Deve-se haver sociedade e, mais ainda, Estado, deve haver um regulamento obrigatório das relações do homem entre si, deve haver um poder. Mas, se devemos ser comandados, queremos sê-lo por nós mesmos. A liberdade natural transforma-se em liberdade social ou política. É politicamente livre aquele que está submetido, sim, mas à vontade própria e não alheia. Com isso apresenta-se a síntede de princípio das formas políticas e sociais. (KELSEN, 2000, p. 28)

Neste sentido, Kelsen não se afasta dos autores contratualistas, onde a liberdade natural (o estado de natureza) e a liberdade política/civil são conceitos que estão em esferas difusas, e para que uma forma de liberdade seja possível é necessário que a outra seja renunciada.

A importância da ideia de liberdade é explicada por ser originada na própria "alma humana" do indivíduo. Para Kelsen, apenas duas formas de organização política é possível na modernidade: a democracia e a autocracia. Somente a democracia é capaz de garantir certo grau de liberdade aos indivíduos, na medida em que produz uma metamorfose na ideia de liberdade contra o domínio estatal (liberdade natural) para liberdade na produção da ordem estatal. Desta forma a liberdade política, passa a ser considerada como a autodeterminação do indivíduo na sociedade, como participação do indivíduo na formação da vontade do Estado. Esta é essencialmente a forma da liberdade democrática, onde os indivíduos não apenas possuem uma esfera de ação livre da vontade estatal, mas sim que participam diretamente da formação da vontade coletiva a que estão submetidos.

A ordem estatal é criada pelos próprios indivíduos. A abordagem mais marcante desta análise da liberdade, é afirmação que em qualquer organização social, necessariamente haverá sempre uma relação dialética entre a força da vontade individual (autonomia) e a força do normativismo social (heteronomia), que, segundo ele, pesa sobre a vontade individual como um tormento (KELSEN, 2000, p. 27-28). Em última análise, a liberdade do indivíduo é irrealizável, e o indivíduo encontra-se "preso" na liberdade democrática ou da coletividade, na medida em que se ele não pode subtrair-se a ordem social, ele somente pode participar na produção do aperfeiçoamento dessa ordem. Mesmo assim, o autor afirma que é impossível que o indivíduo seja capaz de subtrair-se dessa ordem quando ela não está de acordo com sua vontade. Portanto, o sistema democrático mesmo que seja o mais eficiente para produzir um amplo 
estado de liberdade, ainda assim exige que haja indivíduos não livres.

A ideia de igualdade não é central para a construção doutrinária de Kelsen. Distanciando-se das concepções mais clássicas da democracia, onde o princípio da igualdade estava na base do fundamento democrático, o austríaco não dedica muito espaço em sua reflexão para esse princípio.

A igualdade apresenta-se a partir da concepção de que nenhum homem deve estar submetido a outro homem. Esta noção também se encontra no sentido primitivo do homem, na medida em que este rejeita o peso da vontade alheia. A ideia básica é que nenhum indivíduo possui maior valor que outro no estado social. Na verdade, para Kelsen os indivíduos são iguais apenas formalmente e no estado democrático de direito. Fora dessa realidade política, os homens são completamente diferentes e possuem vontades distintas. A desigualdade é um fato social, que se apresenta claramente na natureza. $\mathrm{O}$ que se pode entender é que essa desigualdade natural, não deve ser considerada na construção de um sistema democrático. Apesar de a ideologia sistema-democrática exigir que a liberdade seja o valor fundamental, para que este sistema seja possível, será necessário que todas as desigualdades intrínsecas no estado natural do homem, sejam abolidas perante o Estado, para que haja uma ordem justa. É necessário que haja uma igualdade de direitos e perante a lei. Desta forma, a igualdade torna-se um princípio importante para que a democracia seja construída, permitindo que os indivíduos sendo juridicamente considerados como iguais, sejam todos livres na ordem social. Sem a igualdade, Kelsen não concebe democracia, na medida em que todos devem ser considerados como sujeitos capazes de aperfeiçoar a ordem estatal.

A igualdade funciona como princípio complementar ao princípio da liberdade. Da pressuposição de que se nem todos os indivíduos são livres em uma ordem social, é preciso que pelo menos a maior parte deles seja. O Estado dessa forma deve produzir as normas sociais observando a liberdade, se não de todos, pelo menos da maioria dos indivíduos. A democracia é capaz de coexistir ao lado de frustrações e insatisfações de grupos de indivíduos. Não é possível que todos os indivíduos sejam livres na ordem social. Se isso fosse possível, Kelsen salienta que não haveria a necessidade de normas sociais. $\mathrm{O}$ valor da liberdade não é absoluto, apesar de todos os indivíduos serem considerados como iguais no processo de construção da ordem social. 
Liberdade e Igualdade na Democracia

A base para compreensão do fundamento filosófico da democracia, segundo a doutrina kelseniana, está na síntese entre os princípios da liberdade e igualdade. São esses os dois postulados básicos que compõem e justificam qualquer sistema político que possa ser considerado como democrático. Para Kelsen, o conceito de liberdade é essencial e constitui o fundamento básico. A ideia de igualdade é secundária, e serve apenas para reforçar a noção de liberdade presente no sistema político (KELSEN, 2000, p. 99).

$\mathrm{O}$ indivíduo politicamente livre é aquele que pode participar da criação da ordem estatal. Se todos querem ser livres, mas por outro lado se deve existir um poder para regular a vida social, então é necessário que todos os indivíduos devam participar na formação da ordem democrática. A liberdade é concebida na democracia como a autodeterminação política do indivíduo. Os indivíduos ao perceberem que são iguais, não admitem que sejam comandados pela vontade de outro indivíduo semelhante (ibid. p. 25). Desta forma, a igualdade na natureza humana traz a necessidade de liberdade e de construção de uma ordem social onde nenhum homem seja escravo de outro. Essa ideia apresentada por Kelsen é antiga e remonta a experiência política democrática ateniense do século IV a.C.

O sistema democrático, enquanto sistema social, apesar de representar uma restrição à liberdade natural do indivíduo, ainda assim é o regime político que permite um maior grau de liberdade aos indivíduos. Como para Kelsen todo estado de sociedade é inevitavelmente um estado onde existirão indivíduos não livres, onde o peso da vontade alheia ou da ordem social mesmo não estando de acordo com a vontade individual deve valer objetivamente e, portanto, ser obedecida por todos. O sistema democrático apresenta-se como o melhor meio para garantir pelo menos um grau de liberdade a um número maior de indivíduos. O princípio da maioria, que é adotado em todas as democracias contemporâneas, significa a efetivação dessa noção de que a maior parte dos indivíduos deve ser livre. Essa posição aproxima-se da filosofia utilitarista de Bentham e Mill, que considera que o governo tem a função de garantir a felicidade ou bem-estar ao maior número possível de cidadãos.

Como na ordem social haverá sempre aqueles que estarão em desacordo com as decisões do Estado e sendo impossível uma coincidência absoluta entre o ser e o dever-ser, Kelsen ressalta que é preciso reduzir ao máximo o número 
daqueles indivíduos que se sintam inconformados com a ordem estatal. Em toda sua doutrina democrática, percebe-se uma preocupação por vezes explícita, por vezes tácita, de preservar os direitos das minorias.

Para entender a doutrina de Kelsen, é preciso ressaltar que o estado social deve sempre considerar as posições minoritárias, mesmo que seja construído com base na vontade da maioria. Apesar de ser a vontade da maioria a fonte absoluta para a criação da ordem social, a democracia somente é possível a partir da proteção dos direitos das minorias políticas (KELSEN, 2000, p 70). É preciso que o sistema democrático permita um grau de liberdade onde se em um dado momento a minoria seja vencida em seus anseios, por outro lado é possíve que uma eventual minoria possa tornar-se uma maioria. Isso é o que Kelsen denomina de política de compromisso. Para atingir esse objetivo, Kelsen ressalta a centralidade do papel do parlamento. A democracia, neste sentido, pode ser vista como uma política de compromisso, onde os representantes devem sempre considerar o acordo e os compromissos feitos com a minoria. Se houvesse aniquilação dos anseios da minoria, já não seria mais possível haver democracia, visto que só existiria a partir daí um governo dos mais fortes. O fato é que o número, a quantidade, nunca foi considerado como um elemento de força que deve se sobrepor aos outros, segundo Kelsen. "Por isso, o princípio democrático de liberdade parece exigir que a possibilidade de uma decisão imposta à minoria se reduza ao mínimo; maiorias qualificadas, possivelmente unanimidade, são consideradas garantias de liberdade individual" (KELSEN, 1988, p.29).

$\mathrm{O}$ indivíduo no sistema democrático é considerado livre apenas na medida em que vota com a maioria e, assim, consegue ter força para transformar sua vontade na ordem social. Se por outro lado ele vota de acordo com a minoria, ou muda de ideia com o passar do tempo e já não concorda com a maioria, ele torna-se não livre. Segundo Kelsen, mesmo com seus defeitos, essa é a única forma de democracia que pode ser realizada na prática. Sempre haverá pessoas que se sentem oprimidas pela ordem estatal. O que a democracia pode fazer é reduzir esse número de pessoas ao mínimo possível para que a ordem seja considerada como justa. "O fato de se continuar falando de autonomia e considerando cada um como submisso à sua própria vontade, enquanto o que vale é a lei da maioria, é um novo progresso da metamorfose da ideia de liberdade" (KELSEN, 1988, p. 30). 
O princípio da maioria é o único capaz de estabelecer uma ordem onde o maior número de indivíduos possa ser livre, aproximando-se ao máximo da ideia de liberdade natural. Ou seja, seria apenas um instrumento aproximativo da ideia de liberdade, já que está em sua essência é impossível na prática social. Além disso, o princípio majoritário pressupõe que as vontades dos indivíduos sejam iguais, e que todos devam ser considerados igualmente no processo de formação da vontade majoritária. O princípio da igualdade não suporta a ideia de que um homem seja comandado por outro, visto que todos são iguais. Por isso, Kelsen ressalta que o sujeito de poder se desloca do indivíduo-igual para a entidade anônima do Estado. Esta entidade é formada pela vontade coletiva e torna-se o sujeito de poder, diferentemente da personificação que há em sistemas autoritários, onde um homem exerce o poder. A liberdade encontra-se apoiada no maior número, mas para ser considerada como democrática é preciso que seja observada a vontade da minoria. Somente em autocracias é que há uma tentativa de eliminação do menor número discordante, das opiniões e visões de mundo contrárias. Em um sistema que pretende garantir a maior liberdade aos indivíduos, a vontade de todos é levada em consideração, mesmo que a ordem seja estabelecida pela vontade majoritária.

Comparando a ideologia com a realidade, que é a principal preocupação de Kelsen, percebe-se que a ideia de democracia sofre bastante transmutação, mas que nem por isso afeta a sua natureza de ser o regime que permite a maior liberdade. O povo ainda é considerado como a origem da criação da ordem estatal, mesmo que o povo seja o maior número. A liberdade com sua transformação, ainda continua sendo o valor central para a democracia. $\mathrm{O}$ fundamento da liberdade na democracia une o princípio da maioria e a vontade parlamentar. Não sendo possível a criação de a ordem social ser realizada através do voto direto de todos os cidadãos, devido a fatores como a imensidão dos territórios e da população dos Estados modernos, a ordem social é criada de forma indireta pelo parlamento, e não mais de forma direta como ocorria na Grécia Antiga. O parlamentarismo apresenta-se, então, como uma conciliação entre a exigência democrática de deliberdade e o princípio da distribuição do trabalho - causa da diferenciação e condicionante de qualquer progresso técnico-social. (KELSEN, 2000, p. 47).

Apesar disso, percebe-se uma insatisfação com a democracia parlamentarista moderna. Kelsen afirma 
que tanto pela extrema direita, quanto pela extrema esquerda é possível identificar um desprezo pelos princípios do regime parlamentarista. $\mathrm{O}$ que é interessante notar é que para Kelsen apenas o parlamento é capaz de realizar a democracia, portanto qualquer forma de aversão ao parlamentarismo também é uma aversão à própria democracia. A luta contra a autocracia dos XVIII e XIX foi essencialmente uma luta a favor do parlamentarismo. Para o autor é impensável haver um regime que se proponha a defender a liberdade e a igualdade dos indivíduos se esse regime não se guiar pelo sistema parlamentar. Os Estados contemporâneos são bastante amplos e complexos, impossibilitando que a liberdade dos ndivíduos seja realizada de forma direta, a partir da participação de todos os indivíduos no debate público. Apenas o princípio parlamentar que cria uma classe de representantes políticos que se dedicam exclusivamente a deliberar pelo interesse público, que pode realizar o método democrático. A democracia é indireta e os cidadãos se limitam a criar e a controlar os indivíduos eleitos para representação no parlamento. Além disso, Kelsen ressalta a importância dos partidos políticos no processo de formação da vontade diretiva do Estado. Os partidos políticos são grupos que agregam os homens com os mesmos interesses e visões de mundo e que agem no sentido de alcançar o poder do Estado para fazer valer seus objetivos. Sem esses grupos organizados, Kelsen afirma que não é possível haver o princípio parlamentar e, desta forma, a liberdade política estaria comprometida.

Todos os instrumentos que Kelsen defende para a realização da democracia moderna estão relacionados com o fato básico de que a liberdade não pode ser realizada em seu estado puro na esfera social, mas deve admitir certos princípios que não estão em sua essência, como os partidos políticos e parlamentarismo.

\section{O Wesen e o Wert da Democracia}

A elaboração teórica de Kelsen desde o início considera o fato básico da diferenciação entre a ideologia e a realidade, conforme citado anteriormente. Essas duas esferas de análise são distintas pelo autor, na tentativa de excluir determinados equívocos que possam permitir uma má interpretação do sistema democrático. Contudo, não é possível entender a ideologia e a realidade, ou a essência (wesen) e o valor (wert) da democracia separadamente. 
Ao tratar do ser ou Wert, Kelsen centra-se, sobretudo na análise do valor da liberdade enquanto princípio filosófico desse sistema. O tema deste trabalho também está relacionado ao dever ser da democracia, ou seja, é mais importante entender o valor ou Wert da democracia e como a liberdade e a igualdade são justificadas como base filosófica desse sistema. Contudo, é preciso apontar certos esclarecimentos do wesen da democracia, para que se possa entender como esses princípios são realizados empiricamente no mundo contemporâneo.

Após a complexificação da sociedade moderna, com o surgimento dos Estados modernos, dos processos de industrialização e, sobretudo, do surgimento da divisão social do trabalho, tornou-se impossível que os ideais democráticos de participação direta do povo na formação da vontade do Estado fossem realizados. O ideal da democracia direta, que estava presente na doutrina dos republicanos durante o período da Revolução Francesa, não pode mais ser sustentado diante da complexidade dos sistemas estatais contemporâneos. Kelsen percebe esse fato e afirma que o único meio possível de realização da democracia nas sociedades contemporâneas seria a partir do parlamento. $\mathrm{O}$ parlamento seria o único órgão nas democracias contemporâneas capaz de ajustar-se à divisão social do trabalho, na medida em que haveria um corpo profissional de políticos dedicados aos processos de tomada de decisão, e por outro lado garantiria o máximo possível de liberdade política, na medida em que aos cidadãos caberia a prerrogativa de controle e criação do corpo parlamentar.

\section{Conclusão}

A base para compreensão do fundamento filosófico da democracia, segundo a doutrina kelseniana, está na síntese entre os princípios da liberdade e igualdade. São esses os dois postulados básicos que compõem e justificam qualquer sistema político que possa ser considerado como democrático. Para Kelsen, o conceito de liberdade é essencial e constitui o fundamento básico. A ideia de igualdade é secundária, e serve apenas para reforçar a noção de liberdade presente no sistema político. O indivíduo politicamente livre é aquele que pode participar da criação da ordem estatal. Se todos querem ser livres, mas por outro lado se deve existir um poder para regular a vida social, então é necessário que todos os indivíduos devam participar na formação da ordem 
democrática. A liberdade é concebida na democracia como a autodeterminação política do indivíduo. Os indivíduos ao perceberem que são iguais, não admitem que sejam comandados pela vontade de outro indivíduo semelhante. Desta forma, a igualdade na natureza humana traz a necessidade de liberdade e de construção de uma ordem social onde nenhum homem seja escravo de outro. Essa ideia apresentada por Kelsen é antiga e remonta a experiência política democrática ateniense do século IV a.C.

O sistema democrático, enquanto sistema social, apesar de representar uma restrição à liberdade natural do indivíduo, ainda assim é o regime político que permite um maior grau de liberdade aos indivíduos. Como para Kelsen todo estado de sociedade é inevitavelmente um estado onde existirá indivíduos não-livres, onde o peso da vontade alheia ou da ordem social mesmo não estando de acordo com a vontade individual, deve valer objetivamente e, portanto, ser obedecida por todos. O sistema democrático apresenta-se como o melhor meio para garantir pelo menos um grau de liberdade a um número maior de indivíduos. $\mathrm{O}$ princípio da maioria, que é adotado em todas as democracias contemporâneas, significa a efetivação dessa noção de que a maior parte dos indivíduos deve ser livre.
Com este trabalho foi possível conhecer o pensamento político de um dos maiores juristas do século passado. Hans Kelsen partindo da influência de autores contratualistas, elabora uma doutrina democrática que compreende a liberdade como elemento essencial nos sistemas políticos onde há justiça. A liberdade social é o meio que a democracia deve seguir para que permita uma aproximação da liberdade natural dos indivíduos. O que diferencia o pensamento de Kelsen de doutrinas políticas anteriores é a conjugação dos princípios filosóficos da liberdade e da igualdade com a realidade possível nos Estados contemporâneos. A realidade possível, para o autor, é a existência de um órgão colegiado criador das normas sociais, que é criado e controlado por indivíduos. Por outro lado, a igualdade é para o autor a igualdade de direitos, ou igualdade na liberdade, onde todos indivíduos devem possuir direitos e liberdades públicas que o permitam participar na criação da ordem pública indiretamente.

Referências Bibliográficas 
ARISTÓTELES. Política. 3. ed. Brasília:Editora Universidade de Brasília, 1997.

BOBBIO, Norberto. Liberalismo e democracia. São Paulo: Brasiliense, 1988. Norberto Bobbio: o filósofo e a política: antologia. Rio de Janeiro: Contraponto, 2003.

KELSEN, Hans. A democracia. São Paulo: Martins Fontes, 2000. O que é justiça? A justiça, o direito e a política no espelho da ciência. 3. ed. São Paulo: Martins Fontes, 2001. O problema da justiça. 4. ed. São Paulo: Martins Fontes, 2003. - Teoria geral do direito e do estado. Brasília: Editora Universidade de Brasília, 1990. 